10. Rahmanova E.N. Prava cheloveka. Prestupnost'. Globalizaciya. Opyt kompleksnogo kriminologicheskogo issledovaniya: Monografiya. M.: Rossijskaya akademiya pravosudiya, 2009. $192 \mathrm{~s}$.

11. Saulyak O.P. Sushchnost' pravoporyadka: teoretiko-metodologicheskoe issledovanie. Avtoref. dis. ... doktora yuridicheskih nauk po special'nosti 12.00.01. M., RANHiGS pri Prezidente RF, 2010.53 s.

12. Akademik RAN Mihail Gorshkov - o tom, zachem nuzhna sociologiya i kakuyu cenu imeet dlya vlasti chelovek // Rossijskaya gazeta. 2013. 8 noyabrya. № 252.

13. Ebzeev B.S. Konstituciya, vlast' i svoboda v Rossii: Opyt sinteticheskogo issledovaniya. M.: Prospekt, 2014. 336 s.

14. Atamanchuk G.V. Novoe gosudarstvo: poiski, illyuzii, vozmozhnosti. M.: «Slavyanskij dia$\log », 1996.223 \mathrm{~s}$.

15. Problemy teorii gosudarstva i prava / Pod red. M.N. Marchenko. 2-e izd., pererab. i dop. M.: Norma: INFRA-M, 2012. 656 s.

DOI: $10.22394 / 2074-7306-2019-1-3-38-44$

\title{
О СИСТЕМЕ ПОЛИТИКО-ПРАВОВЫХ ЦЕННОСТЕЙ, ЗАКРЕПЛЕННЫХ В ПРЕАМБУЛАХ КОНСТИТУЦИЙ БЫВШИХ РЕСПУБЛИК СССР
}

Линкин
Виктор
Николаевич кандидат юридических наук, доцент кафедры

«Теория и истории государства и права», Донской государственный технический университет (344010, Россия, г. Ростов-на-Дону, пл. Гагарина, 1). E-mail: linkinviktor@gmail.com

\section{Аннотация}

В статье на основе комплексного использования сравнительного, статистического и герменевтического методов исследования, с целью получения синергетического эффекта, проведены исследования преамбул конституций вновь образованных государств постсоветского периода. Автором предложена оценка содержания преамбул конституций, как первоисточника общественных запросов, рефлексирующего на особенностях государственной политики, концентрата целей и задач, поставленных обществом перед собой и государством. Анализ смыслового содержания понятий «гражданский мир» и «национальное согласие» из преамбул конституций выявляет скрытый смысл посланий народов, населяющих постсоветские государства.

Ключевые слова: конституция, преамбула, постсоветские государства, права и свободы, гражданский мир, национальное согласие, языковые единицы, герменевтика, общественный запрос, разрешение конфликтов.

Конец двадцатого века был ознаменован распадом многонациональных государств (СССР, Югославия, Чехословакия). Государства, вышедшие из их состава, искали теперь уже свой собственный путь развития. После распада СССР на соответствующей территории возникли 15 новых (или хорошо забытых старых) государств. Каждое государство теперь руководствовалось только своими интересами и интересами своего народа.

В современной России и во многих постсоветских государствах СССР укоренилось мнение, что распад союза - это геополитическая катастрофа. Распад СССР отразился на всех сферах жизнедеятельности общества. Образование новых суверенных государств было нежданным событием не только для власти СССР, но и в первую очередь для его населения.

В течение 1992 года пять вновь образованных государств приняли собственные конституции (Латвия, Туркменистан, Литва, Эстония, Узбекистан). Бойкот прибалтийскими республиками «Всесоюзного референдума о сохранении СССР» 17 марта 1991 года предшествовал провозглашению государственного суверенитета, в отличие от Туркме- 
нистана и Узбекистана, чей народ высказался за сохранение Союза (в референдуме участвовали и показали результат 97,9 \% и 93,7 \% [1].

Распад СССР драматически повлиял на судьбы миллионов людей, не готовых к жизни в условиях рынка и конкуренции. Произошла смена общественно-экономической формации и, как следствие, деформация всех сфер общественной жизни: трудовой, образовательной, медицинской, информационной, политической, потребительской, религиозной. Первый этап сопровождался энтузиазмом идей новой жизни, общественным консенсусом, результатом чего стали конституции постсоветских государств. Конституции являлись воплощением общественного договора, условиями, на которых молодые государства начинали собственную, суверенную жизнь.

Вновь образованные государства воплощали дебютные идеи в своих конституциях, что стало своеобразным признаком их самостоятельности. Рассматривая через герменевтический подход вводную часть конституций бывших союзных республик, мы стремимся продемонстрировать запрос (потребности) гражданского общества на указанные в преамбулах блага.

Именно языковые технологии преамбулы конституции могут продемонстрировать особенности общественного запроса, который в дальнейшем раскрывается и интерпретируется законодателем в конституционно-правовых нормах.

Научные исследования в двадцатом веке языковых средств и технологий Людвига Витгенштейна, Мартина Хайдайгера, Мишеля Фуко открыли и показали миру роль и смысловое значение слова, как способа определения «всего» в современной действительности.

При распаде коммунистической системы и крушении ее идей, поиск истины стал для постсоветского общества первоочередной задачей. Процесс поиска иногда сопровождался ужасающими сопутствующими явлениями (финансовые пирамиды, экстрасенсы, националистические идеи и т. д.). Общество в поиске истины живо реагировало на различные изменения, даже деструктивного характера. Истина искалась повсюду.

По Л. Витгенштейну, истина - это приоритет первого обозначения [2]. Исходя из этого тезиса, общество искало первоначальное состояние, устраивающие всех его членов - режим согласия. Представляется бесспорным утверждение, согласно которому становление согласия - первооснова построения цивилизованного общества и главнейший принцип построения государства.

Важнейший элемент любого исследования - используемый исследователями метод. В современных условиях глобализации метод научно-правового исследования выходит за пределы юридической науки и взаимодействует с другими отраслями научного знания. Г. Еллинек отмечал, что «всякий, приступающий к исследованию основных социальных проблем, не может не почувствовать с первых шагов отсутствия глубоко продуманной методологии» [3].

Сравнительный метод исследования позволит выявить общее и особенное в различных государственных образованиях сходного типа, для более точного определения особенностей их функционирования и перспектив развития. С помощью сравнительного метода исследования постсоветских государств будут определены общие закономерности воплощения государственного строительства в различных государствах, а также общие ценности и пути их развития. В итоге будет определен фундамент, в котором заключены основные общественные запросы на момент создания на постсоветском пространстве новых государственных образований.

В рамках исследования сравнительный и статистический методы будут использованы комплексно, с учетом значительного количества объектов исследования. Такой подход позволит в преамбулах конституций государств постсоветского пространства изначально определить и вычленить основные общественные запросы, а потом выявить их сходства. 
По причине неоднородности понимания различных явлений и процессов, идея, заложенная в тексте, может передаваться неодинаково, что обусловливает необходимость применения герменевтического метода исследования.

Герменевтический метод применяется по отношению к текстам, в передаче идеологического содержания, где значительную роль играют стилистически маркированные языковые единицы.

Конституции большинства стран мира содержат примерно одинаковый набор прав, свобод, независимо от времени и условий их принятия, различия же заключаются в закреплении и обозначении именно общественных запросов, результатом реализации которых являются государственные и национальные ценности.

Рассмотрев преамбулы конституций стран постсоветского пространства, нами были выделены отдельные языковые единицы (маркеры) (табл).

Таблица

\section{Количество употребления в преамбулах конституций определенных языковых единиц}

\section{Языковая единица}

Количество упоминаний

Гражданский мир и согласие, гражданское согласие, дружбы, мира и безопасности с другими народами, жить в мире и согласии, национальное согласие, гражданского мира и национального согласия, жить в единстве, мире и согласии

Ответственность перед нынешним и будущими поколениями, ответственность перед Богом, собственной совестью, предшествующими, нынешним и грядущими поколениями, ответственность перед прошлым, нынешним и будущим поколениями, пользы для нынешних и грядущих поколений, ответственность и долг перед прошлыми, нынешними и будущими поколениями

История государственного строительства, история развития государственности, фундаментальных принципах армянской государственности, продолжая многовековые традиции своей государственности, национальной государственности, развивать и укреплять кыргызскую государственность, создавший много веков тому назад Литовское государство, созидая государственность на исконной казахской земле, непрерывную государственность молдавского народа, опираясь на исторический опыт развития узбекской государственности

Демократическое, правовое, социальное, правовое, светское государство, обеспечивающее верховенство законов, демократического общественного строя, экономической свободы, социального и правового государства

Суверенная государственность, государственной независимости, суверенная страна

Часть мирового сообщества, желая занять достойное место в мировом сообществе

Приверженность общечеловеческим ценностям

Утверждения гражданского общества, сознавая себя миролюбивым гражданским обществом

Суверенная воля народа, народовластие

Благополучие и процветание России, благополучие каждого,

Вера в добро и справедливость

Незыблемость демократических основ

Укрепление и развитие Родины

Справедливость, свободу и безопасность

Защищать независимость, суверенитет

Идеалам свободы, равенства и согласия

Удовлетворению интересов граждан иного этнического происхождения

4

4

2

2

2

1

1

1

1

1

1

1


Рассмотрев полученные данные, можно отметить, что большинство государств определяют согласие (гражданское и национальное) и мир, как обязательный общественный запрос для построения государства. В преамбулах конституций, согласие и мир, закрепляются в различных смысловых вариациях:

- утверждая ...... гражданский мир и согласие (Россия) ${ }^{1}$;

- заботясь об укреплении гражданского согласия (Украина);

- желая обеспечить гражданское согласие (Беларусь) ${ }^{3}$;

- во имя обеспечения общего благосостояния гражданского согласия для потомков (Армения) ${ }^{4}$;

- жить в условиях дружбы, мира и безопасности с другими народами и в этих целях осуществлять взаимовыгодное сотрудничество (Азербайджан)

- исходя из заветов наших предков, жить в мире и согласии, в гармонии с природой (Киргизия);

- радея о национальном согласии (Литва)

- стремление жить в мире и согласии со всеми народами мира (Молдова);

- в целях обеспечения гражданского мира и национального согласия (Узбекистан);

- уважая равноправие и дружбу всех наций и народностей (Таджикистан) ${ }^{10}$;

- стремясь обеспечить навеки гражданский мир и национальное согласие (Туркменистан) ${ }^{11}$.

В постсоветском правовом пространстве понятия «гражданский мир» и «национальное согласие» в различных смысловых вариациях - достаточно новое явление. Анализ смыслового сопровождения (содержания) понятий гражданский мир и согласие из преамбул конституций выявляет скрытый смысл посланий народов, населяющих постсоветские государства.

Российский народ определил содержание понятий мира и согласия, как укрепление и установление; украинский народ, как беспокойство и тревожность; белорусский народ - стремление к благополучию; азербайджанский - взаимные обязательства договаривающихся сторон, при наличии чего-либо, их обусловливающего; армянский и киргизский народы - пребывание в мире и согласии; литовский народ - содействие в национальном согласии; молдавский народ - настойчиво добиваться, быстро направляться; узбекский и туркменский народы - полностью удовлетворять какие-либо потребности, предоставлять достаточные материальные средства к жизни; таджикский народ - высоко ценить, отдавать предпочтение равноправию и дружбе.

Рассматривая задачи достижения гражданского мира и государственной безопасности, И.А. Умнова (Конюхова) определяет гражданский (социальный мир), как отношения внутри государства, характеризующие состояние общества - жить в согласии, без

\footnotetext{
${ }^{1}$ Конституция Российской Федерации. URL: http://constitution.kremlin.ru (дата обращения: 20.04.2019).

2 Конституции государств Европы: В 3 т. / Под общей редакцией и со вступительной статьей директора законодательства и сравнительного правоведения при Правительстве Российской Федерации Л.А. Окунькова. М.: Норма, 2001.

3 Там же.

4 Там же.

5 Там же.

${ }^{6}$ Конституция Киргизии. URL: http://www.president.kg/ru/konstitutsija (дата обращения: 20.04.2019).

${ }^{7}$ Конституции государств Европы: В 3т. /Под общей редакцией и со вступительной статьей директора законодательства и сравнительного правоведения при Правительстве Российской Федерации Л.А. Окунькова. - М. Издательство Норма, 2001.

8 Там же.

9 Конституция Узбекистана. URL: http://www.press-service.uz/ru/constitution/index (дата обращения: 20.04.2019).

10 Конституция Таджикистана. URL: http://www.constcourt.tj/rus (дата обращения: 20.04.2019).

11 Конституция Туркменистана. URL: http://turkmenistan.gov (дата обращения: 20.04.2019)
} 
вооруженных столкновений между политическими и (или) идеологически ориентированными группировками, социальными группами населения, способными порождать вооруженные конфликты (локальные и общенациональные) [4].

Национальное согласие и гражданский мир могли, для некоторых полинациональных государств, стать фундаментом построения государственности. Национальные общности, населяющие государство, можно сравнить с двумя шахтерами, которые копают с разных сторон горы в поисках одной и той же цели (мира и согласия), и при этом каждый не знает о цели другого. Нет в мире национальностей, которые не заняты построением мира, правда, многие до сих пор применяют вариант войны для достижения мира, а компромиссы считают за слабость.

Закрепленные в конституциях нарративы «гражданский мир» и «национальное согласие» имели свою первоочередную цель - разрешить существующие конфликты и являться превентивным средством против будущих конфликтов.

Понятия «гражданский мир» и «национальное согласие» появились не только в текстах конституций, наблюдался всплеск использования данных понятий во всей литературе постсоветского пространства.

Частота упоминаний понятий «гражданский мир» и «национальное согласие» была проанализирована при помощи программы «Google Books Ngram Viewer», которая производит анализ частотности применения языковых единиц на основе внесенных в нее восьми миллионов русскоязычных источников, начиная с XVIII века и по сегодняшний день, основываясь на законе больших чисел - чем больше эмпирических данных исследования, тем меньше оказывается воздействия случайностей на объект. На наш взгляд, вышеуказанное количество источников позволяет получить достаточно релевантные данные.

\section{Google Books Ngram Viewer}

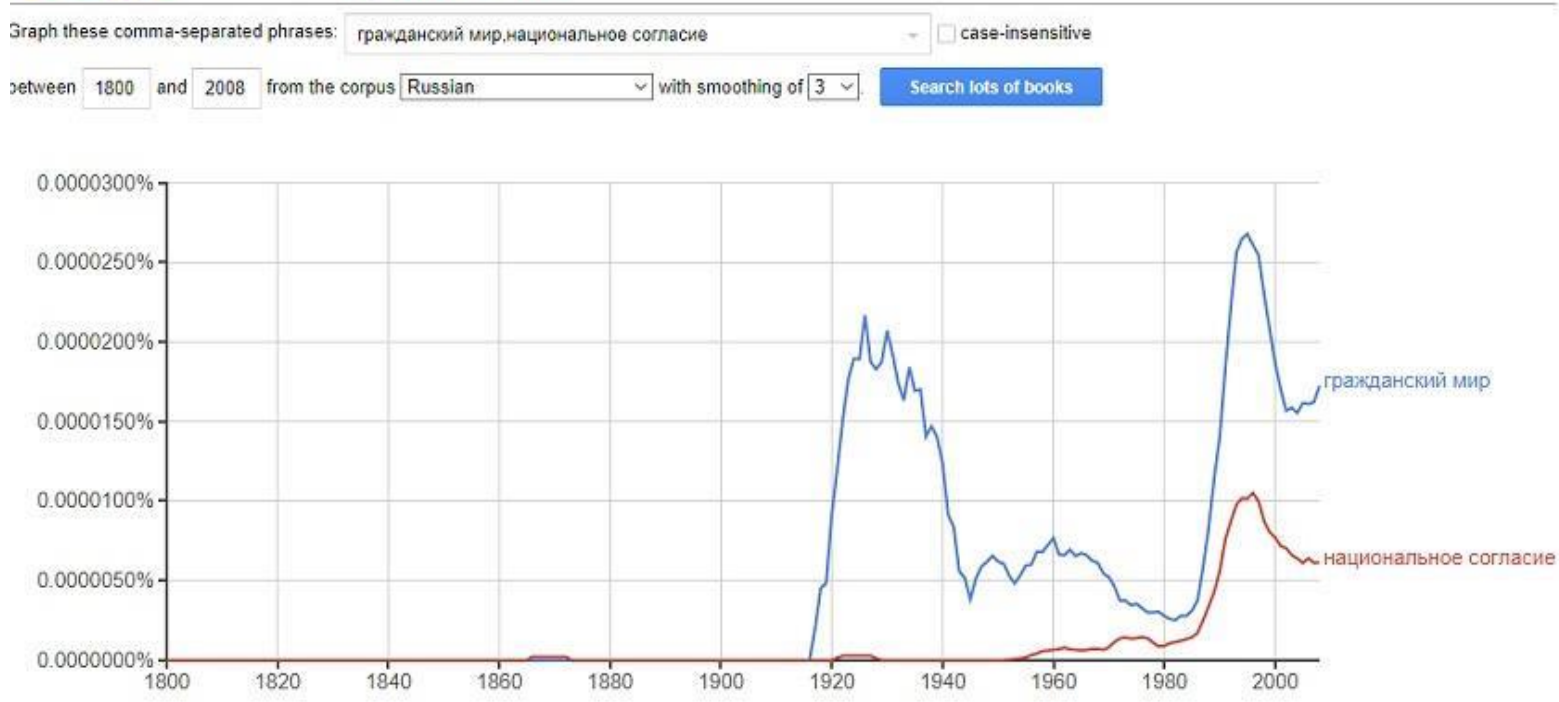

График. Частота употребления в рускоязычной литературе словосочетаний «гражданский мир» и «национальное согласие»

Результаты демонстрируют небывалый рост частоты использования данных словосочетаний в период принятия конституций бывших республик СССР

На графике отчетливо видно, что понятия «гражданский мир» и «национальное согласие» с конца восьмидесятых годов двадцатого века часто использовались в литературе, и пошли на спад только в середине девяностых. Амплитуда графика имеет различие в $800 \%$.

Одним из важнейших факторов образования нового государства является конституция, как выражение воли народа. Нельзя конституцию насадить насильно, период ок- 
троированных конституций уходит в прошлое. Принятие новой конституции требует наличия в государстве как минимум минимального общественного консенсуса.

Преамбула конституции представляет собой первоначальный общественный запрос, который уже конкретизируется в самой конституции, посредством закрепления прав и свобод человека. Естественное право является той средой существования человеческого общества, которая создает предпосылки образования государства на основе мира и согласия.

С наступлением времени потрясений, общество вновь образованных государства установили своей целью мир и согласие. Государство - стихия мира и союз правды и на первоначальном этапе своего существования не может обойтись без гражданского мира и национального согласия.

Общество свой запрос выражает через доступные ему формы: политические (путем участия в политической жизни); культурные (через творчество), религиозные (духовное развитие) и другие самые различные формы, где представители различных частей общества коммуницируют вне зависимости от противоречий и разногласий.

Анализ языка литературы позволяет определить, то в чем нуждалось общество на определенных этапах своего развития, что было для него общей идеей. Именно мир и согласие занимало ума людей во время геополитических потрясений. Мир и согласие представляет собой материальный базис, который появляется из нематериального общественного запроса.

\title{
Литература
}

1. Об итогах референдума СССР, состоявшегося 17 марта 1991 года (Из сообщения Центральной комиссии референдума СССР) // Известия. 1991. 27 марта.

2. Витгенштейн Л. Философские работы / Пер. с нем. М. С. Козловой и Ю. А. Асеева. Ч. І. М.: Гнозис, 1994. 612 с.

3. Еллинек Г. Общее учение о государстве. СПб.: Юрид. центр Пресс, 2004. 752 с.

4. Применение Конституции Российской Федерации как правовая гарантия гражданского мира и безопасности государства»: Монография / Под редакцией И.А. Умновой (Конюховой). М.: РГУП, 2017. 185 с.

Linkin Viktor Nikolaevich, PhD in Law, Associate Professor Department "Theory and History of State and Law". Don State Technical University (1, square Gagarin, Rostov-on-Don, 344010, Russian Federation), senior lecturer of the department "Constitutional and international law", Rostov branch of the Russian Customs Academy (20, Budennovskiy Avenue, Rostov-on-Don, 344002, Russian Federation).

E-mail: linkinviktor@gmail.com

\section{ON THE SYSTEM OF POLITICAL AND LEGAL VALUES ENSHRINED IN IN THE PREAMBLE OF THE CONSTITUTIONS OF THE FORMER REPUBLICS OF THE USSR}

\begin{abstract}
In the article, based on the comprehensive use of comparative, statistical and hermeneutic methods of research, in order to obtain a synergistic effect, studies of the preambles of the constitutions of the newly formed states of the post-Soviet period were conducted. The authors proposed an assessment of the content of the Preamble of Constitutions, as the primary source of public inquiries, reflecting on the specifics of state policy, the concentration of goals and tasks set by society to itself and the state. Analysis of the semantic content of the concepts of civil peace and consent from the preambles of the constitutions reveals the hidden meaning of the messages of the peoples inhabiting the post-Soviet states.
\end{abstract}

Key words: constitution, preamble, post-Soviet states, rights and freedoms, civil peace, national harmony, language units, hermeneutics, public request, conflict resolution. 


\title{
References
}

1. Ob itogah referenduma SSSR, sostoyavshegosya 17 marta 1991 goda (Iz soobshcheniya Central'noj komissii referenduma SSSR) // Izvestiya. 1991. 27 marta.

2. Vitgenshtejn L. Filosofskie raboty / Per. s nem. M. S. Kozlovoj i YU. A. Aseeva. CH. I. M.: Gnozis, 1994. 612 s.

3. Ellinek G. Obshchee uchenie o gosudarstve. SPb.: YUrid. centr Press, 2004. 752 s.

4. Primenenie Konstitucii Rossijskoj Federacii kak pravovaya garantiya grazhdanskogo mira i bezopasnosti gosudarstva»: Monografiya / Pod redakciej I.A. Umnovoj (Konyuhovoj). M.: RGUP, 2017. $185 \mathrm{~s}$.

\section{ТЕНДЕНЦИИ РАЗВИТИЯ ГОСУДАРСТВЕННО-ПРАВОВОЙ СИСТЕМЫ РЕСПУБЛИКИ АБХАЗИЯ}

\author{
Бжания руководитель Аппарата Парламента Республики Абхазия, \\ Baдuм старший преподаватель кафедры государства и права юриди- \\ Владимирович ческого факультета, Абхазский государственный универси- \\ тет, аспирант кафедры теории права и государства, истории \\ и философии, Сочинский государственный университет. \\ Абхазский государственный университет \\ (384904, Республика Абхазия, г. Сухум, ул. Университетская, 1) \\ E-mail: vadimraa@mail.ru
Квачева Пелагея Ивановна доктор юридических наук, профессор, профессор кафедры
теории права и государства, истории и философии,
Сочинский государственный университет
(354000, Российская Федерация, Краснодарский край г. Сочи,
ул. Советская, 26 a)
E-mail: kvacheva46@mail.ru

Аннотация

Вследствие провозглашения независимости Республики Абхазия, закрепления ее конституционно-правового статуса как самостоятельного государства, актуальным вопросом становится состояние современной государственно-правовой системы данного государства. Правовая система отражает созданные и закрепленные в нормативных правовых актах государственные институты власти во взаимосвязи с институтами гражданского общества, а также правовой статус человека и гражданина, призваны в свою очередь обеспечить стабильность и перспективу развития государственности Абхазии и достойный уровень жизни граждан Республики. Система законодательства требует особого внимания и детальной проработки, поскольку Республика Абхазия встала на путь формирования различных институтов как единой эффективно действующей системы государственной власти, обеспеченной верховенством права и закона.

В данной научной статье проведено исследование законодательства Республики Абхазия, а также рассмотрены тенденции дальнейшего его развития.

Ключевые слова: Республика Абхазия, государство, Конституция, закон, Президент, Парламент, государственно-правовая система, верховенство права, законодательство, общество, государственная власть, нормативно-правовой акт.

Историко-правовой предпосылкой становления государственно-правовой системы Республики Абхазия является распад СССР и в последующем война между Республикой Грузия и Республикой Абхазия в период с 1992 по 1993 гг. Политико-правовые процессы конца 1980-х гг., связанные с дезинтеграцией государства СССР, привели к возможности осуществления оформления суверенных политических образований в каче- 